\title{
ECTROPOTHECIUM SODALE (HYPNACEAE, BRYOPHYTA) - NEW TO INDIA FROM THE PENINSULA
}

\author{
P. M. Biju, R. SReebha and A. E. D. Daniels* \\ Bryology Laboratory, Department of Botany and Research Centre, Scott Christian College, \\ Nagercoil-629 003, Tamil Nadu, India; *E-mail: dulipdaniels@yahoo.co.uk
}

(Received 13 October, 2016; Accepted 25 January, 2017)

The moss Ectropothecium sodale is added here to the flora of India from the peninsular part of the country. A brief description with illustrations and a photographic plate are provided.

Key words: Eastern Ghats, Ectropothecium sodale, Western Ghats

\section{INTRODUCTION}

So far 10 species of Ectropothecium Mitt. have been reported from the Western Ghats (Daniels 2010, Lal 2005, Schwarz 2013). In the course of studying the bryoflora of the Indira Gandhi National Park in Anamalais of the Western Ghats and Kolli Hills of the Eastern Ghats, a species of Ectropothecium Mitt. was collected at both places, which was later identified as Ectropothecium sodale (Sull.) Mitt. This discovery is a new record for India and the Western Ghats as well, thereby raising the number of species to 11 . However, this is the first record of this genus for the Eastern Ghats. A brief description with illustrations and a photographic plate are provided. Specimens are housed at SCCN.

Ectropothecium sodale (Sull.) Mitt. is closely allied to E. zollingeri (Müll. Hal.) A. Jaeger but can be readily distinguished as per the following key.

Key to the species

1a Stem leaves distinctly falcate; pseudoparaphyllia linear-lanceolate, 1 to 3 cells wide at base

E. sodale

$1 \mathrm{~b}$ Stem leaves straight to faintly falcate; pseudoparaphyllia lanceolate, 2 to 11 cells wide at base

E. zollingeri 


\section{Ectropothecium sodale (Sull.) Mitt.}

(Figs 1-19)

Basionym: Hypnum sodale Sull., Proc. Amer. Acad. Arts 3: 78 (1854); E Ectropothecium sodale (Sull.) Mitt., J. Linn. Soc., Bot. 10: 180 (1868); M. Higuchi and Z. Iwats., J. Hattori Bot. Lab. 75: 89 (1994).

= Ectropothecium circinnatulum Thér., Diagn. Esp. Var. Nouv. Mouss. 8: 6 (1910); Bull. Acad. Int. Géogr. Bot. 21: 6 (1910).

$=$ Ectropothecium cupressinatulum Broth. et Paris, Oefvers. Förh. Finska Vetensk.-Soc. 53A (11): 34 (1911). - Type: Eimeo Island, Society Islands, in herb. Sullivant 125 (FH).
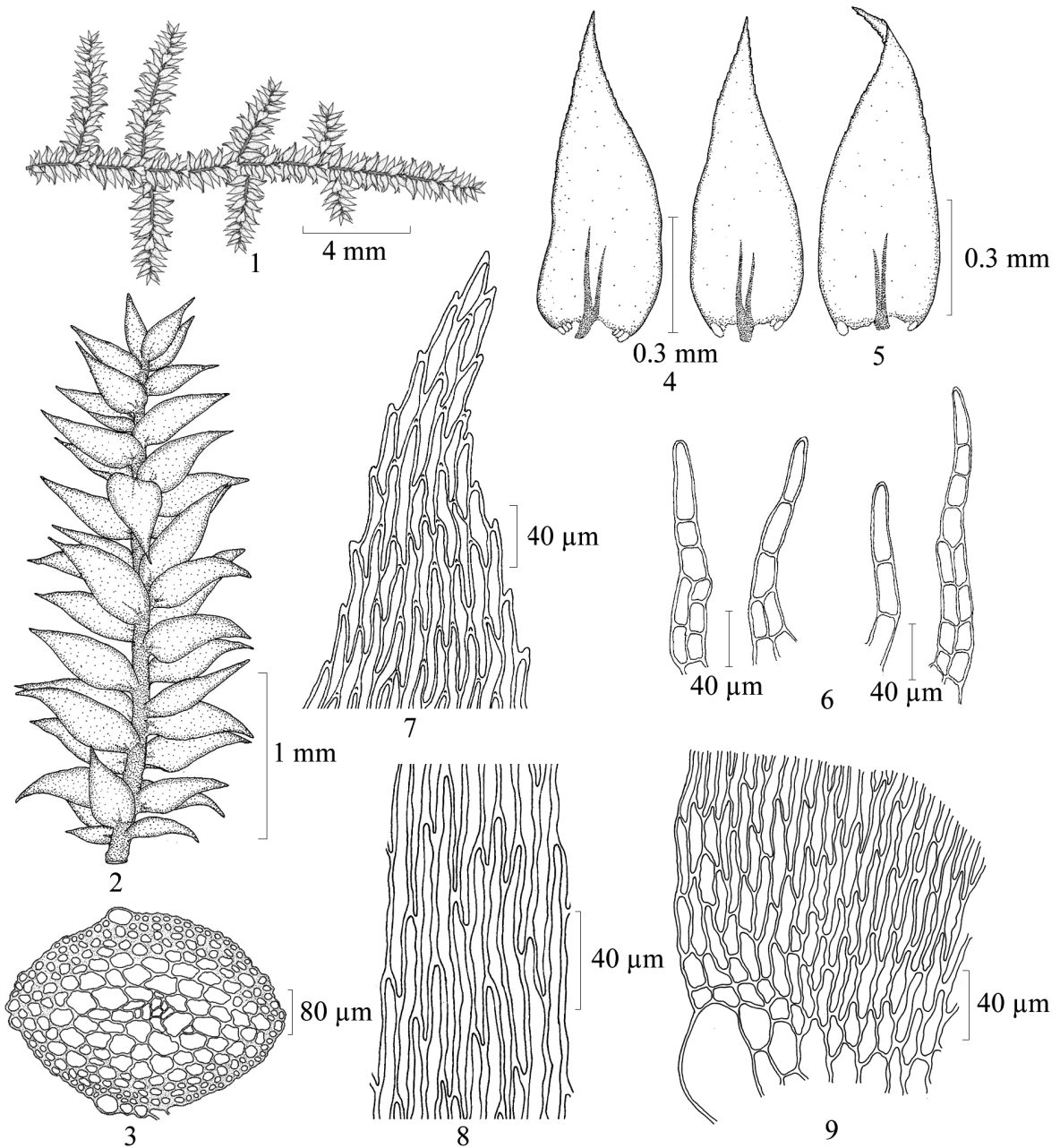

4
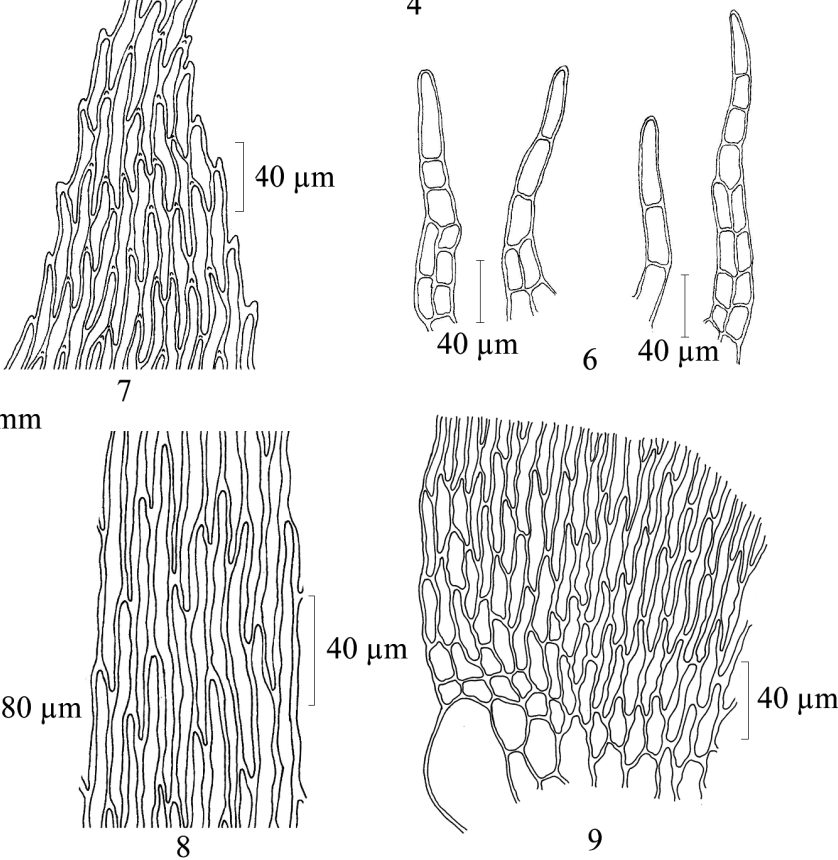

Figs 1-9. Ectropothecium sodale (Sull.) Mitt. $-1=$ plant; 2 = portion of plant; $3=$ cross section of stem; 4 = stem leaves; 5 = branch leaf; $6=$ stem pseudoparaphyllia; $7=$ leaf apical cells; $8=$ leaf median cells; 9 = leaf basal cells (drawn from Daniels, A. E. D., 8784) 

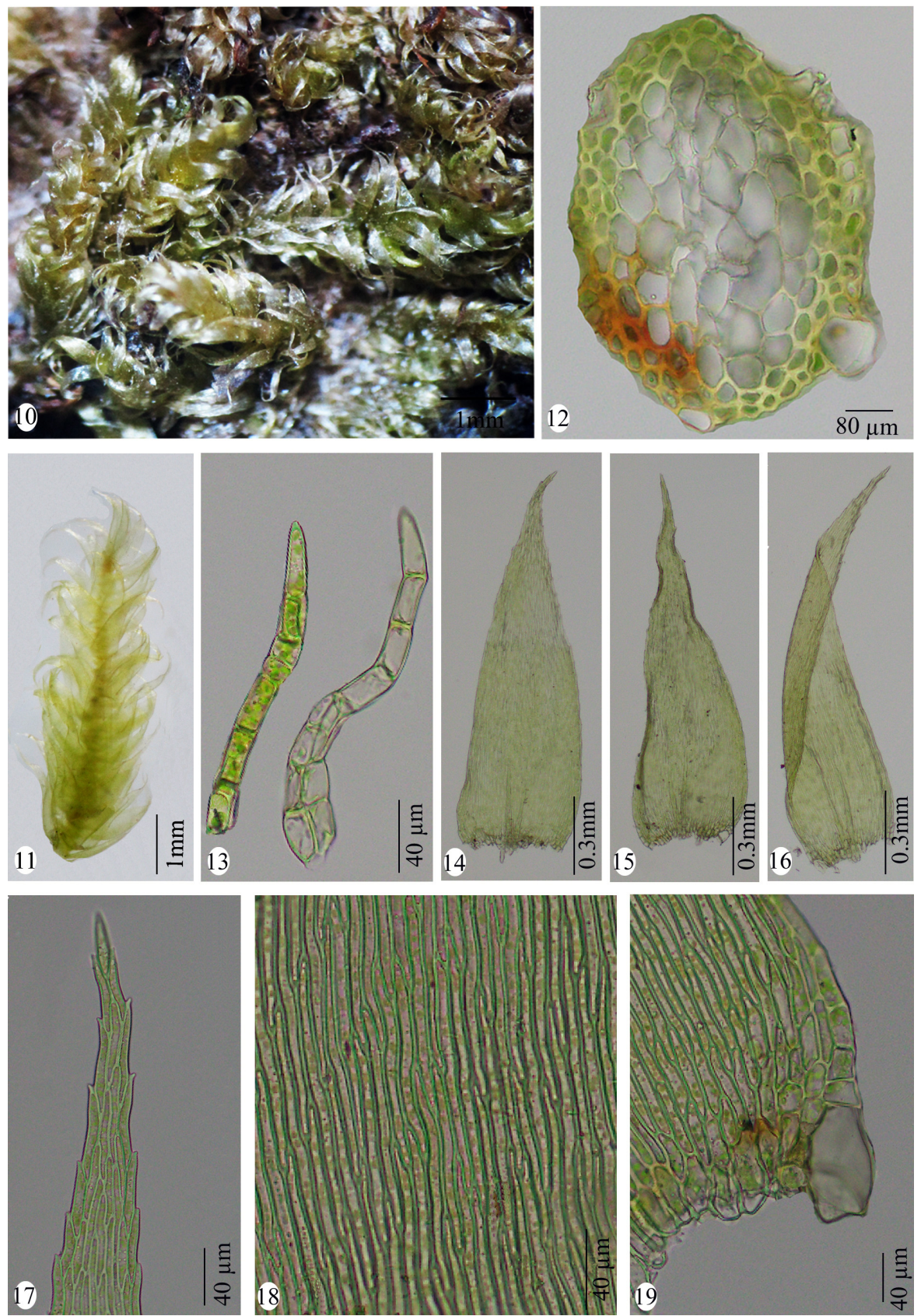

Figs 10-19. Ectropothecium sodale (Sull.) Mitt. $-10=$ plants; $11=$ portion of plant; $12=$ cross section of stem; 13 = stem paraphyllia; $14-15$ = stem leaves; 16 = branch leaf; 17 = leaf apical cells; 18 = leaf median cells; 19 = leaf basal cells (photographed from Biju, P. M., 1465 p.p.) 
Plants autoicous, in dense mats, glossy, yellow-green. Stems creeping, $2-3 \mathrm{~cm}$ long, regularly or irregularly pinnately branched, $c a 0.48 \times 0.34 \mathrm{~mm}$ in cross section, rounded to ovate, with a faint central strand; cortex 3- or 4-layered; cells 6-12 $\times 4-6 \mu \mathrm{m}$, thick-walled, rounded-quadrate; medullary ones 12-36 × 10-20 $\mu \mathrm{m}$, quadrate-hexagonal, thin-walled. Pseudoparaphyllia 0.1-0.15 $\times 0.012-0.016 \mathrm{~mm}$, linear-lanceolate, foliose, 1 to 3 cells wide at base. Stem leaves $0.1-0.11 \times 0.03-0.04 \mathrm{~mm}$, lanceolate, distinctly falcate, acuminate; costa double, faint; branch leaves erectopatent, $0.6-0.8 \times 0.18-0.24 \mathrm{~mm}$, ovatelanceolate, concave, denticulate at margin above; apical cells elongate-rhom-

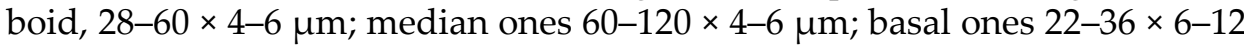
$\mu \mathrm{m}$, irregularly rectangular; alar cells differentiated by a few cells with one at extreme angle the largest; costa double, faint. Sporophyte not seen.

Habitat: Terricolous in degraded evergreen forests and corticolous on Scolopia crenata (Wight et Arn.) Clos (Flacourtiaceae), in evergreen forests and tea plantations, 820-1,300 m; saxicolous in degraded evergreen forests, ca 1,240 m.

Distribution: Fiji, Marquesas Isl., New Caledonia, New Guinea, Samoa, Society Islands and India: Western and Eastern Ghats of Tamil Nadu (Coimbatore and Namakkal).

Specimens examined: Western Ghats, Tamil Nadu, Coimbatore Dist., Valparai, Anali estate. Alt.: ca 870 m a.s.l., Daniels, A. E. D. (8784, 8787, 8790, 8797 p.p.), 11.08.2012; Valparai, Karian Shola. Alt.: ca 820 m a.s.l., Daniels, A. E. D. and Kariyappa, K. C. (9719 p.p.), 24.09.2014; Valparai, Umayandimudukku. Alt.: ca 1,200 m a.s.l., Daniels, A. E. D. and Kariyappa, K. C. (9377, 9378 p.p., 9379 p.p., 9382 p.p., 9384 p.p.), 19.02.2013; Valparai, Umayandimudukku, near waiting shelter, Alt.: ca 1,300 m a.s.l., Sreebha, R. and Kariyappa, K. C. (9905 p.p.), 4.02.2015. - Eastern Ghats, Tamil Nadu, Namakkal Dist., Kolli Hills, Perumakka shola. Alt.: ca 1,240 m a.s.l., Biju, P. M. (1465 p.p.), 21.01.2016.

Acknowledgements - We thank the Tamil Nadu State Forest Department for permission to explore the study areas. AEDD thanks the Department of Science and Technology (DST), New Delhi, and Ministry of Environment and Forests and Climate Change (MoEFCC), New Delhi, for financial assistance and the Principal, Scott Christian College, for facilities.

\section{REFERENCES}

Daniels, A. E. D. (2010): Checklist of the bryophytes of Tamil Nadu. - Arch. Bryol. 65: 1-118. Lal, J. (2005): A checklist of Indian mosses. - Bishen Singh Mahendra Pal Singh, Dehra Dun, India, $164 \mathrm{pp}$.

Schwarz, U. (2013): An updated checklist of bryophytes of Karnataka. - Arch. Bryol. 181: 1-42. 